\title{
Pre-treatment of porcine pulmonary xenograft with desmopressin: a novel strategy to attenuate platelet activation and systemic intravascular coagulation in an ex-vivo model of swine-to-human pulmonary xenotransplantation
}

Kim YT, Lee HJ, Lee SW, Kim JY, Wi HC, Park SJ, Bae SJ, Kang HJ. Pre-treatment of porcine pulmonary xenograft with desmopressin: a novel strategy to attenuate platelet activation and systemic intravascular coagulation in an ex-vivo model of swine-to-human pulmonary xenotransplantation.

Xenotransplantation 2008; 15: 27-35. (c) 2008 Blackwell Munksgaard

Abstract: Background: Von Willebrand factor (vWF) has been proposed as a major contributor to the development of coagulopathy in pulmonary xenotransplantation. Pretreatment of donor swine with 1-deamino8-D-arginine vasopressin (DDAVP), an analog of vasopressin, can reduce the content of vWF in pulmonary xenografts. Here, we investigate the effects of DDAVP pre-treatment in an ex-vivo perfusion model of pulmonary xenotransplantation.

Methods: We set up and performed the ex-vivo perfusion using porcine pulmonary accessory lobes and fresh human whole blood $(\mathrm{n}=12)$.

Half of the donor swine were given $3 \mu \mathrm{g} / \mathrm{kg}$ DDAVP intravenously for 3 days before ex-vivo perfusion (DDAVP group) and half of them were left untreated (control group). The porcine lung was perfused with fresh blood for $1 \mathrm{~h}$ and changes in the following parameters were monitored: pulmonary arterial pressure, pulmonary vascular resistance, blood cell counts, fibrinogen, antithrombin, platelet factor 4, D-dimer, C3a, C4d, and xenoreactive IgM. The release of Gala1-3Gal xenoantigen ( $\alpha \mathrm{Gal})$ from porcine lung which had been perfused and retained for 30 min with human blood was assessed by enzyme-linked immunosorbent assay using $\alpha$ Gal-binding lectin.

Results: Both DDAVP and control groups showed typical findings of immediate pulmonary dysfunction: an increase of pulmonary vascular resistance and sequestration of leukocytes and platelets after ex-vivo perfusion. However, in the DDAVP group, the increase of platelet factor 4, C3a, and $\mathrm{C} 4 \mathrm{~d}$ after perfusion was attenuated compared to that in the control group. The release of $\alpha \mathrm{Gal}$ after blood retention was significantly lower in the DDAVP group than that of the control group.

Conclusion: Pre-infusion of DDAVP to the donor swine was beneficial in attenuating platelet activation as well as complement/coagulation activation. These effects of DDAVP are likely to relate to the reduction of porcine $\mathrm{vWF}$ content in the xenograft. Therefore, the modulation of $\mathrm{vWF}$ secretion in donor lungs could be an additional therapeutic way to reduce systemic coagulopathy in pulmonary xenotransplantation.

\author{
Young Tae Kim, ${ }^{1,2,3}$ Hyun Joo \\ Lee, ${ }^{1,3}$ Sang Woo Lee, ${ }^{1}$ Ji Yeon \\ Kim, ${ }^{1,4}$ Hyun Cho Wi, ${ }^{1}$ Sun Jung \\ Park, ${ }^{1,2}$ Sung Jin $\mathrm{Bae}^{3}$ and Hee \\ Jung Kang ${ }^{4}$ \\ ${ }^{1}$ The Xenotransplantation Research Center, Clinical \\ Research Institute, Seoul National University \\ Hospital, Seoul, Korea, ${ }^{2}$ Cancer Research Institute, \\ Seoul National University, Seoul, Korea, \\ ${ }^{3}$ Department of Thoracic and Cardiovascular Surgery, \\ Seoul National University, Seoul, Korea, \\ ${ }^{4}$ Department of Laboratory Medicine, Hallym \\ University College of Medicine, Anyang, Korea
}

Key words: complement - 1-deamino-8-d-arginine vasopressin - lung - platelet - von Willebrand factor - xenotransplantation

Abbreviations: $A U$, artificial unit; DDAVP, 1-deamino-8-d-arginine vasopressin; ELISA, enzyme-linked immunosorbent assay; $\alpha \mathrm{Gal}$, Gal $\alpha 1-3 \mathrm{Gal}$ xenoantigen; GSL, Griffonia simplicifolia lectin; PAEC, porcine aortic endothelial cells; PBS, phosphatebuffered saline; PF4, platelet factor 4; PG, prostaglandin; PVR, pulmonary vascular resistance; TBS, Tris-buffered saline; vWF, von Willebrand factor.

Address reprint requests to Hee Jung Kang, Department of Laboratory Medicine, Hallym University College of Medicine, 896 Pyeongchon-dong, Dongan-gu, Anyang-si, Gyeonggi-do 431-070, Korea (E-mail: kangheejung@hallym.ac.kr)

Received 29 October 2007;

Accepted 21 November 2007 


\section{Introduction}

Xenotransplantation using porcine organs is a promising alternative solution to overcome the shortage of human donor organs. Hyperacute rejection, the first hurdle for xenotransplantation, could be overcome using porcine organs genetically engineered to overexpress human complement regulatory proteins or to lack the major xenoantigen, Gal $\alpha 1-3 \mathrm{Gal}(\alpha \mathrm{Gal})$ [1]. These strategies enabled us to prolong the survival of porcine xenografts transplanted to non-human primates up to several months or weeks in cardiac and renal transplantation [2-5]. However, in the case of pulmonary xenotransplantation, xenografts undergo a rapid failure immediately after exposure to human or primate blood [6-8], characterized by elevated pulmonary vascular resistance (PVR) and pulmonary edema associated with vascular thrombosis [7], despite these strategies. Intravascular thrombosis accompanying systemic coagulopathy is a main pathologic feature of pulmonary xenografts while tissue necrosis and hemorrhages are the main attributes of cardiac or renal xenograft hyperacute rejection [9].

Von Willebrand factor (vWF) has been proposed as a major contributor to the development of coagulopathy in pulmonary xenotransplantation $[9,10]$. Porcine vWF released from activated endothelial cells of xenografts not only promotes platelet adhesion and activation on the surface of endothelial cells, but also provides binding sites for xenoreactive antibodies because of its abundant $\alpha$ Gal moiety. The immune complexes of xenoreactive antibodies and vWF on swine endothelial cells are shed into the circulation and lead to systemic coagulation abnormality [11]. We have previously demonstrated that pre-treatment of donor swine with 1-deamino-8-D-arginine vasopressin (DDAVP), an analog of vasopressin, can reduce the content of $\mathrm{vWF}$ in pulmonary xenografts and ameliorate platelet sequestration in the swine-tocanine pulmonary xenograft model [12]. Accordingly, we asked if DDAVP pre-treatment would be beneficial in swine-to-human xenotransplantation. Consequently, we investigated the effect of DDAVP pre-treatment of donor swine in an ex-vivo perfusion pulmonary xenotransplantation model.

\section{Materials and methods}

Treatment of donor with DDAVP

All of the animals in the study were treated humanely in compliance with the "Guide for the Care and Use of Laboratory Animals" published by the National Institutes of Health (NIH Publication No. 86-23, revised 1985). DDAVP treatment was performed as previously described [12]. Briefly, six adult donor swine (22 to $35 \mathrm{~kg}$ ) were anesthetized with intramuscular administrations of ketamine hydrochloride $(20 \mathrm{mg} / \mathrm{kg})$ and were intubated and ventilated with $100 \%$ oxygen at a rate of 10 times $/ \mathrm{min}$ with a tidal volume of $12 \mathrm{ml} / \mathrm{kg}$. A 9 Fr. Hickman catheter (Bard Access Systems, Salt Lake City, UT, USA) was inserted into the external jugular vein through the neck incision and the tip was placed in the back. DDAVP $(3 \mu \mathrm{g} /$ $\mathrm{kg}$; Ferring Pharmaceuticals Inc., Suffern, NY, USA) was injected every $12 \mathrm{~h}$ intravenously through the Hickman catheter for 3 days until experiment of ex-vivo perfusion. Blood was sampled at the time of insertion of the Hickman catheter and at the time of organ harvest.

Ex-vivo perfusion set up

The human blood for perfusion was donated from healthy volunteers with B + blood type. The blood donation for research purposes was approved by the Institutional Review Board (IRB H-0412-138013). Four hundred microliters of blood was drawn in a blood bag containing the anticoagulant citratephosphate-dextrose-adenine at 2 to $3 \mathrm{~h}$ before the ex-vivo perfusion. The blood was diluted with the same volume of Hartmann's solution and was added with 2 units $/ \mathrm{ml}$ of heparin sodium and $1.3 \mathrm{mg} / \mathrm{ml}$ of $\mathrm{CaCl}_{2}$. The perfusate was primed in the ex-vivo perfusion circuit.

Lung harvest

Six swine for each DDAVP-infused and control group were used for the experiment. Each animal was anesthetized by intramuscular injection of ketamine hydrochloride $(20 \mathrm{mg} / \mathrm{kg})$, xylazine $(1 \mathrm{mg} / \mathrm{kg})$, and atropine $(0.2 \mathrm{mg})$. After endotracheal intubation, general anesthesia was maintained with sevofluene gas inhalation and intermittent vecuronium administration. The animal was ventilated with a tidal volume of $15 \mathrm{ml} / \mathrm{kg}$ and respiration rates of 15 times/min. A right thoracotomy was placed and the pleural cavity was entered though the top of 7 th rib. The accessory lobe was identified by opening of the pleural investment and the pulmonary artery, vein, and bronchus were dissected. The fissure was carefully divided, avoiding parenchymal damage. The animal was heparinized (300 units $/ \mathrm{kg}$ ) and the accessory lobe was harvested. We divided the pulmonary artery before division of the pulmonary vein to avoid any chance of congestion of the graft. 
After that, the bronchus was divided. The resected accessory lobe was placed in cold preservation solution and the pulmonary artery was cannulated with 8 Fr. aortic cannula, through which prostaglandin (PG) E1 (Eglandin; $4 \mu \mathrm{g} / \mathrm{kg}$, Welfide, Hwaseong, Korea) was infused. The accessory lobe was then perfused with $4{ }^{\circ} \mathrm{C}$ modified Euro-Collins preservation solution $(100 \mathrm{ml} / \mathrm{kg})$. During the perfusion, the accessory lung was ventilated through the bronchial cannula with room air. After perfusion, the pulmonary vein was cannulated for ex-vivo perfusion. A portion of the remaining right upper lobe was sampled for tissue control. The left lung was harvested for the perfusate retaining model.

\section{Ex-vivo perfusion model}

The accessory lobe was connected to the ex-vivo circuit. The perfusion was slowly started and the flow rate was increased gradually to reach $20 \mathrm{ml} /$ min at the pulmonary venous drain site. The graft was ventilated with room-air at $20 \mathrm{ml}$ of tidal volume and 20 times/min of respiratory frequency using a Harvard rabbit ventilator (Hugo Sachs Elektronik, March Hugstetten, Germany). The temperature was maintained at $37^{\circ} \mathrm{C}$ with a heatexchanger and water bath. The perfusion pressure was monitored and blood was sampled at both pulmonary arterial and venous sides at 10,30 , and $60 \mathrm{~min}$ after perfusion. After $60 \mathrm{~min}$ of perfusion, the graft tissue was obtained.

\section{Perfusate retaining model}

The left pulmonary artery was cannulated with a $24 \mathrm{Fr}$. aortic cannula and was perfused with PGE1 and cold Euro-Collins solution. The $200 \mathrm{ml}$ of perfusate (1:1 mixture of human blood and Hartmann's solution) was infused through the cannula at $40 \mathrm{~cm}$ height and the pulmonary vein was clamped. After $30 \mathrm{~min}$ of retention, the pulmonary venous clamp was released and the retained blood was drawn and sampled.

Measurement of blood cell counts and coagulation/complement activation markers

We monitored changes in the following parameters up to $60 \mathrm{~min}$ after reperfusion: blood cell counts, and plasma levels of fibrinogen, antithrombin III, D-dimer, platelet factor 4 (PF4), C3a, and C4d. Blood cell count was measured by ABCvet CBC analyzer $^{\mathrm{TM}}$ (ABX hematology, Montpellier Cedex, France) and coagulation parameters including fibrinogen, antithrombin III, and D-dimer by STA Compact analyzer TM (Diagnostica Stago,
Asnières, France). PF4 was assayed by enzymelinked immunosorbent assay (ELISA) using the Asserachrom ${ }^{\circledR}$ PF4 kit (Diagnostica Stago). The complement activation fragments $\mathrm{C} 3 \mathrm{a}$ and $\mathrm{C} 4 \mathrm{~d}$ were also measured by ELISA kits (Quidel, San Diego, CA, USA). Each parameter was expressed as a percentage of baseline value prior to reperfusion.

Assessment of circulating xenoreactive $\lg \mathrm{M}$ and $\lg \mathrm{G}$

Flow cytometric analysis was performed to detect $\operatorname{IgM}$ and $\operatorname{IgG}$ xenoreactive antibodies. Porcine aortic endothelial cells (PAEC) were purchased from Cell Applications (San Diego, CA, USA). Briefly, $5 \times 10^{5}$ PAEC were incubated with $50 \mu$ of plasma in each tube for $30 \mathrm{~min}$ at $37^{\circ} \mathrm{C}$. In parallel, the cells were incubated with phosphatebuffered saline (PBS) as a negative control, and with a serial dilution of the selected human plasma as a calibrator, which was confirmed to have high titer of IgM antibodies against PAEC. The cells were washed with PBS and then incubated with $100 \mu \mathrm{l}$ of $1: 200$ diluted rabbit anti-human IgM (Dako Corp., Carpinteria, CA, USA) or fluorescein isothiocyanate (FITC)-labeled rabbit antihuman IgG (Dako Corp.) for $30 \mathrm{~min}$ at $37^{\circ} \mathrm{C}$. The cells incubated with unlabeled anti-human IgM were further stained with $1: 200$ diluted FITC-labeled anti-rabbit IgG (ICN Pharmaceuticals, Inc., Aurora, OH, USA) for $30 \mathrm{~min}$ at $37^{\circ} \mathrm{C}$ in the dark. After washing, the cells were fixed with $500 \mu 11 \%$ paraformaldehyde and then analyzed on a FACScan flow cytometer (BD Biosciences, San Jose, CA, USA). The geometric mean fluorescent intensity of each sample was compared to those of the negative control and the calibrator. The amount of binding antibody was expressed as an artificial unit (AU)/ml compared to the mean fluorescent intensity of undiluted calibrator designated as $100 \mathrm{AU} / \mathrm{ml}$.

Measurement of aGal level in perfusate

The level of $\alpha \mathrm{Gal}$ in perfusate was determined by ELISA using a Griffonia simplicifolia lectin (GSL) I-isolectin $\mathrm{B}_{4}$ (Vector laboratories, Burlingame, ON, Canada) coated plate and biotinylated GSL I-isolectin $\mathrm{B}_{4}$ (Vector laboratories). Briefly, the microwell plate was coated with $10 \mu \mathrm{g} / \mathrm{ml} \mathrm{GSL} \mathrm{I-}$ isolectin $\mathrm{B}_{4}$ in carbonate buffer $\left(15 \mathrm{mM} \mathrm{Na} \mathrm{CO}_{3}\right.$ and $35 \mathrm{~mm} \mathrm{NaHCO}, \mathrm{pH} 9.6$ ) overnight at $4{ }^{\circ} \mathrm{C}$. The wells were blocked with Tris-buffered saline (TBS), $\mathrm{pH} 8.0$ containing $1 \%$ bovine serum albumin for $1 \mathrm{~h}$. Each well was reacted with $100 \mu \mathrm{l}$ of $1 / 10$ diluted serum in TBS for $30 \mathrm{~min}$ at $37{ }^{\circ} \mathrm{C}$. The 


\section{Kim et al.}

pooled normal swine serum serially diluted in normal human serum was tested in parallel and used as a control. After being washed with TBS containing $0.05 \%$ Tween 20 , the wells were reacted with $100 \mu \mathrm{l}$ of $1 \mu \mathrm{g} / \mathrm{ml}$ biotinylated GSL I-isolectin $\mathrm{B}_{4}$ for $30 \mathrm{~min}$ at $37^{\circ} \mathrm{C}$ and then $100 \mu \mathrm{l}$ of $1: 2000$ diluted horseradish peroxidase-conjugated streptavidin (Dako Corp.) for $30 \mathrm{~min}$ at $37^{\circ} \mathrm{C}$. After washing, the color reaction was developed and the absorbance at $450 \mathrm{~nm}$ was measured.

\section{Statistical analysis}

Data are expressed as mean \pm standard error of the mean. Comparisons between groups were analyzed using a mixed model which is a type of repeated measures analysis but applicable to analysis of unbalanced data. A P-value less than 0.05 was considered significant.

\section{Results}

Hemodynamic parameters

The pulmonary arterial pressure increased in both control and DDAVP groups after perfusion with human blood $(P=0.001)$. Initially, the mean pulmonary arterial pressure was $37.0 \pm$ $18.0 \mathrm{mmHg}$ and $46.3 \pm 14.6 \mathrm{mmHg}$ in the control and DDAVP groups, respectively. After $60 \mathrm{~min}$ perfusion, it increased to $57.5 \pm 7.3 \mathrm{mmHg}$ and $68.0 \pm 1.0 \mathrm{mmHg}$ in control and DDAVP groups, respectively. Compared to the control group, the DDAVP group showed higher pulmonary arterial pressure $(\mathrm{P}=0.022)$. In the control group, pulmonary vascular resistance increased from $1.8 \pm 0.6 \mathrm{mmHg} / \mathrm{ml} / \mathrm{min}$ to $3.0 \pm 0.5 \mathrm{mmHg} /$ $\mathrm{ml} / \mathrm{min}$, and in DDAVP group, from $2.2 \pm 1.4 \mathrm{mmHg} / \mathrm{ml} / \mathrm{min}$ to $3.0 \pm 0.1 \mathrm{mmHg} /$ $\mathrm{ml} / \mathrm{min}$. There was, however, no statistically significant difference between the two groups $(\mathrm{P}=0.635)$.

DDAVP pre-treatment prevents subsequent hemoconcentration after perfusion.

We monitored blood cell counts in the perfusate prior to and during the perfusion. The initial blood counts were not different between groups. Immediately after the start of perfusion, platelet counts in both groups rapidly decreased within $10 \mathrm{~min}$ and remained low throughout the experiment (Fig. 1). Leukocyte counts gradually decreased with time and there was no difference between groups. Hemoglobin levels in the whole blood gradually increased during the experiment in both

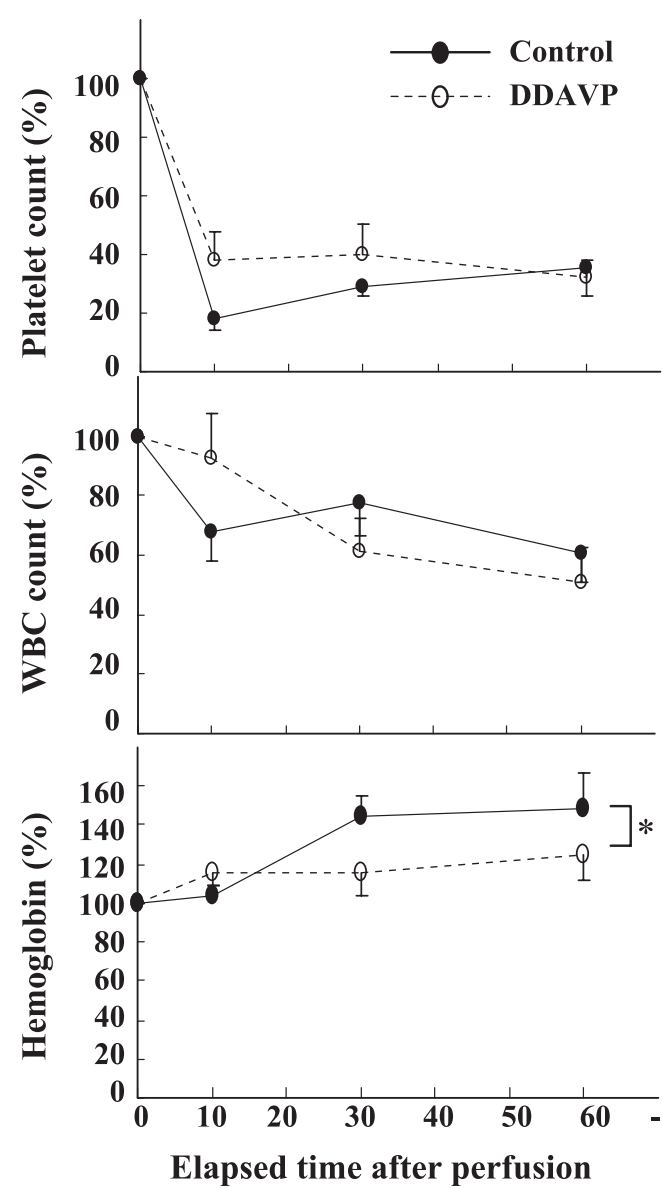

Fig. 1. Changes in hematological parameters: leukocyte and platelet counts and hemoglobin level during ex-vivo perfusion. Half of donor swine were given 1-deamino-8-D-arginine vasopressin (DDAVP, $3 \mu \mathrm{g} / \mathrm{kg}$ ) intravenously every $12 \mathrm{~h}$ for 3 days before ex-vivo perfusion ( $\mathrm{n}=6$ for each group). The porcine lung was perfused with fresh human whole blood and its hematological parameters were monitored for $60 \mathrm{~min}$. Each value at a given time point is expressed as the percentage of the initial measurement. Increases in hemoglobin levels were higher in the control group than that of the DDAVP group $(* \mathrm{P}=0.032)$.

groups but the increase in the control group was higher than that of the DDAVP group $(P=0.032)$, suggesting that hemoconcentration developing during the perfusion was severer in the control group than in the DDAVP group.

DDAVP pre-treatment attenuates systemic coagulation abnormalities and platelet activation

We timely measured the fibrinogen, antithrombin III, and D-dimer levels in perfusate to monitor the coagulation system. Fibrinogen and antithrombin III levels did not change significantly during the perfusion and were not different between groups (Fig. 2). The D-dimer level in the control group occasionally increased during the perfusion and 

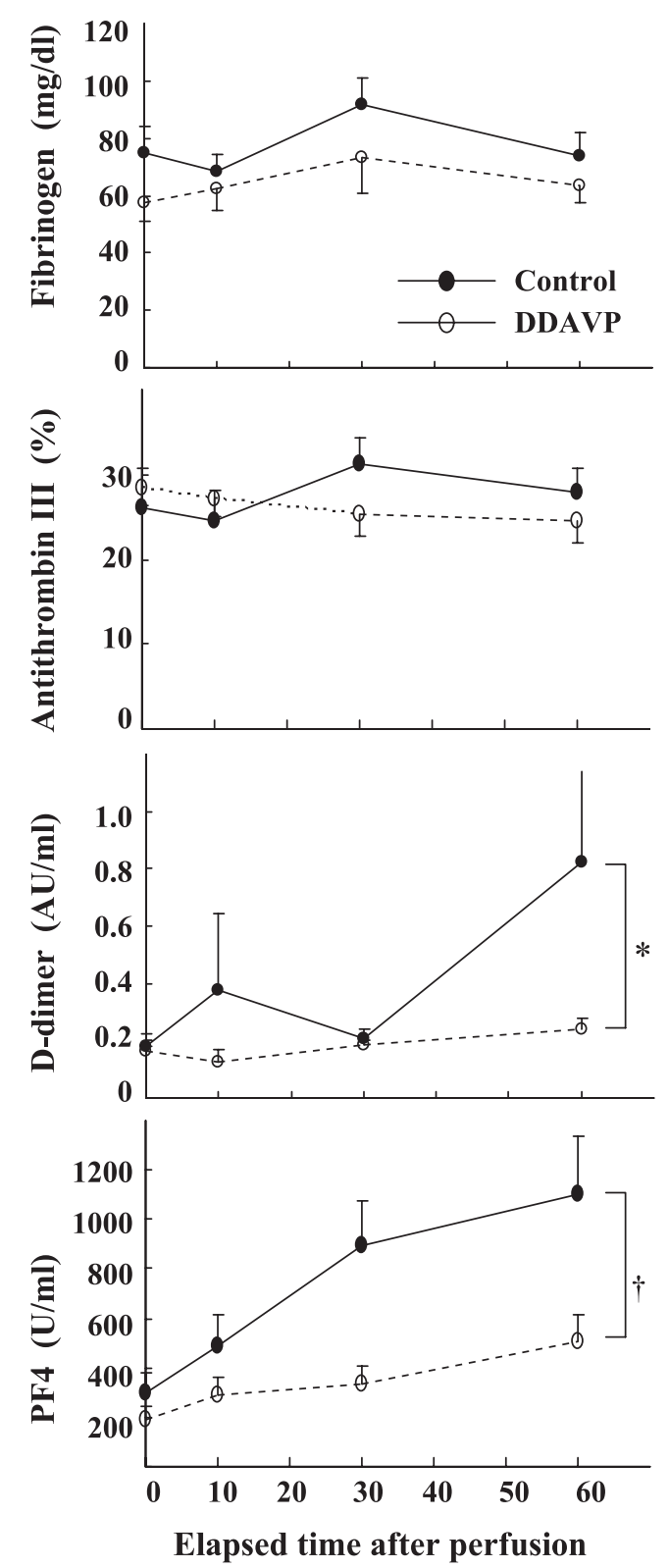

Fig. 2. Changes in coagulation parameters: fibrinogen, antithrombin III, platelet factor 4 (PF4), and D-dimer during exvivo perfusion. Porcine lungs of both DDAVP pretreated and control groups were perfused with fresh human blood for $60 \mathrm{~min}$ and blood was sampled at the given time points. Four coagulation parameters were assayed. In the DDAVP group, D-dimer levels tended to be lower than those of the control group and PF4 levels were significantly lower $(* \mathrm{P}=0.138$; $\dagger \mathrm{P}<0.001)$.

tended to be higher than that of the DDAVP group $(P=0.138)$. In the DDAVP group, the level of D-dimer remained in the normal range throughout the duration of perfusion.

The level of PF4 was also measured to monitor platelet activation. It increased steadily during perfusion in both groups. However, the increase was significantly less in the DDAVP group than that of the control group ( $\mathrm{P}<0.001$, Fig. 2$)$, demonstrating that the extent of platelet activation was less in the DDAVP group compared to controls.

DDAVP pre-treatment reduces complement activation in ex-vivo perfusion model

To evaluate activation of the complement system, $\mathrm{C} 3 \mathrm{a}$ and $\mathrm{C} 4 \mathrm{~d}$ were monitored during perfusion. In the control group, C3a and $\mathrm{C} 4 \mathrm{~d}$ levels increased within $10 \mathrm{~min}$ after perfusion and were maintained at high concentrations throughout the experiment (Fig. 3). However, the DDAVP group showed only a small increase in $\mathrm{C} 3 \mathrm{a}$ and $\mathrm{C} 4 \mathrm{~d}$ levels during the perfusion and their $\mathrm{C} 3 \mathrm{a}$ and $\mathrm{C} 4 \mathrm{~d}$ levels tended to be lower than those of the control group $(\mathrm{P}=0.057,0.058)$, indicating that less systemic complement activation occurred in the DDAVP group.

aGal release from xenograft diminishes in DDAVP pre-treated group

In the next step, we asked how DDAVP pretreatment can reduce complement activation. Porcine $\mathrm{vWF}$ is known to carry a lot of aGal moiety,

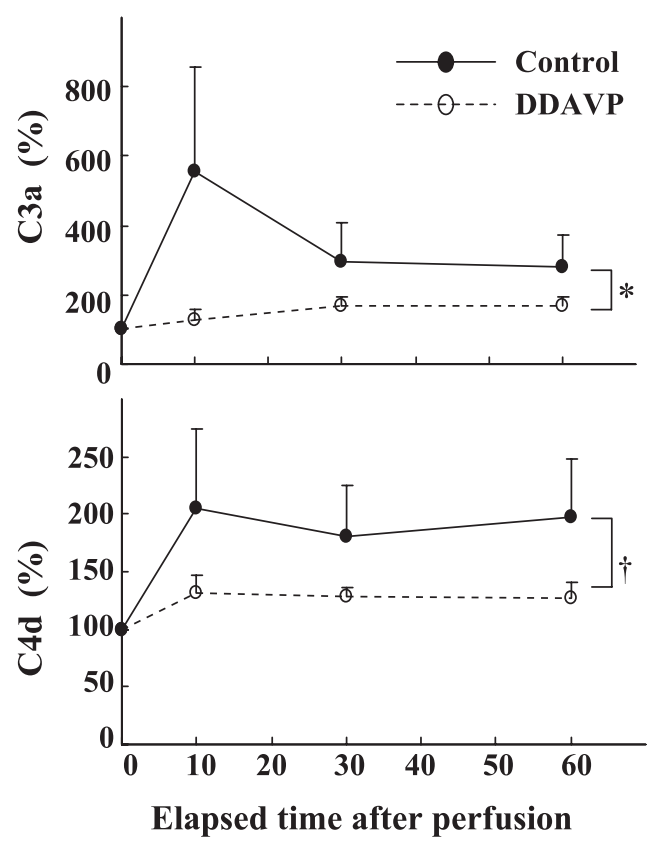

Fig. 3. Changes in complement activation products: C3a and C4d during ex-vivo perfusion. Each DDAVP pretreated and control porcine lung was perfused with fresh human blood for $60 \mathrm{~min}$ and $\mathrm{C} 3 \mathrm{a}$ and $\mathrm{C} 4 \mathrm{~d}$ in the plasma were monitored. C3a and $\mathrm{C} 4 \mathrm{~d}$ levels increased within 10 min after perfusion but the increase of each during perfusion tended to be lower in the DDAVP group than in the control group $(* \mathrm{P}=0.057$; $\dagger \mathrm{P}=0.058$ ). 
which is a main xenoantigen. We hypothesized that depletion of vWF by DDAVP pre-treatment would reduce the amount of $\mathrm{vWF}$ released into the circulation, which would lead to the subsequent reduction of complement activation and systemic coagulation. To determine the amount of released $\alpha \mathrm{Gal}$ antigen, we tried to detect $\alpha \mathrm{Gal}$ by ELISA using GSL I-isolectin $\mathrm{B}_{4}$ in the perfusate timely drawn during the ex-vivo perfusion. However, we failed to demonstrate the presence of $\alpha \mathrm{Gal}$ in the perfusate of either group (data not shown). We designed a perfusate retaining model with the expectation of exaggerated responses of endothelial cells. Each xenograft was perfused and retained for 30 min without circulation, and the perfusate was obtained thereafter. $\alpha \mathrm{Gal}$ was easily detectable by ELISA and its level was higher in the control group than in the DDAVP group ( $\mathrm{P}=0.0317$, Fig. 4$)$, demonstrating that DDAVP pre-treatment reduces the release of $\alpha \mathrm{Gal}$ from xenograft into the circulation.

The initial level of IgM anti-swine antibodies in the perfusate was not different between groups

Complement activation in xenografts is known to depend on the level of anti-swine antibody in circulating blood. The less complement activation in the DDAVP group might have been caused by low anti-swine antibody levels of each blood donor. To exclude this possibility, we measured the level of anti-PAEC antibodies in the blood by flow cytometry. The blood used in each experiment showed a variable level of $\operatorname{IgM}$ antibodies against PAEC, but on average, the initial level of IgM anti-

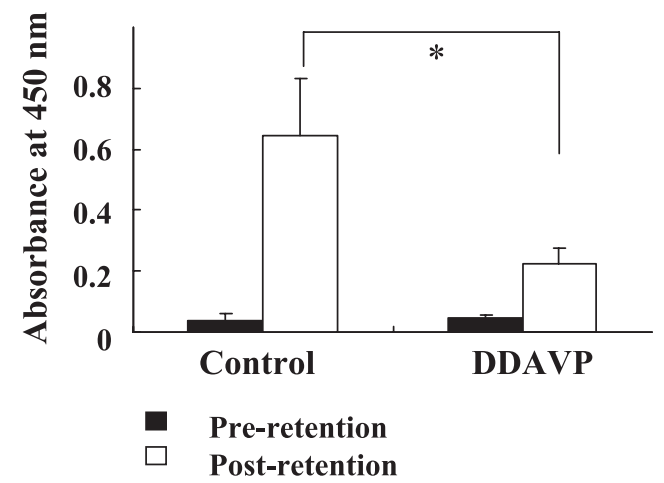

Fig. 4. $\alpha$ Gal release from DDAVP treated and control porcine lungs. Each lung was perfused with fresh human blood and retained for $30 \mathrm{~min}$ ( $\mathrm{n}=6$ for each group). The blood was obtained before and after 30 min retention. Serum $\alpha \mathrm{Gal}$ was captured on GSL I-isolectin $\mathrm{B}_{4}$ coated wells and detected by biotinylated GSL I-isolectin $\mathrm{B}_{4}$ and subsequent color development. $\alpha \mathrm{Gal}$ level was higher in the control group than in the DDAVP group $(* \mathrm{P}=0.0317)$.

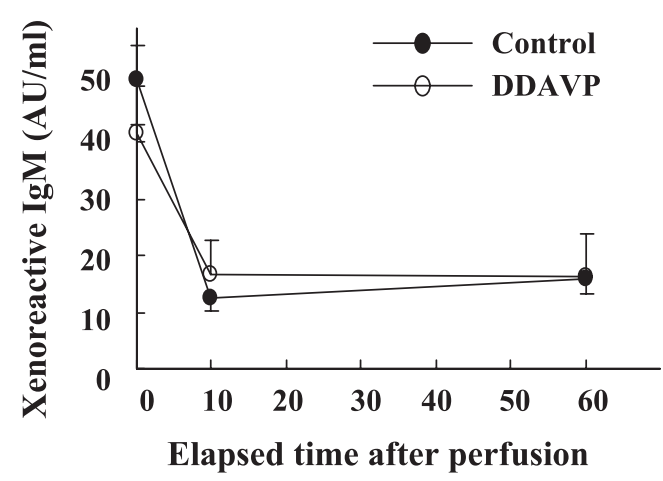

Fig. 5. Change of xenoreactive IgM antibody titer during ex-vivo perfusion. Each lung of DDAVP pretreated or control swine was perfused with fresh human blood for $60 \mathrm{~min}$ and blood was obtained at given time points. Porcine aortic endothelial cells were incubated with each serum, sequentially reacted with rabbit anti-human IgM and FITC-labeled antirabbit $\mathrm{IgG}$, and analyzed with a flow cytometer. The titer of xenoreactive IgM antibody was determined by the mean fluorescent intensity of each serum and expressed as an artificial unit $(\mathrm{AU}) / \mathrm{ml}$ compared to the mean fluorescent intensity of undiluted calibrator designated as $100 \mathrm{AU} / \mathrm{ml}$. There was no significant difference in the initial titer and overall change of xenoreactive $\operatorname{IgM}$ between DDAVP treated and control groups.

PAEC antibodies in the perfusate was not different between groups (Fig. 5). The level of IgM antiPAEC antibodies rapidly decreased after perfusion in both groups suggesting xenoreactive IgM antibodies are captured and sequestered in the xenograft. We tried to measure IgG antibodies against PAEC but failed to detect any significant binding of IgG antibodies to cells (data not shown).

\section{Discussion}

In this study, we demonstrated that DDAVP pretreatment of donor swine reduces adverse responses related to platelet activation and systemic coagulation/complement activation in an ex-vivo perfusion model of pulmonary xenotransplantation. When porcine lung was perfused with fresh human blood, blood platelet counts rapidly dropped and the levels of D-dimer, PF4, and complement activation fragments increased, suggesting that platelets were activated and sequestered into the xenograft, subsequently resulting in intravascular coagulation and complement activation. However, in DDAVP pre-treated group, the degree of increase for D-dimer, PF4, C3a, and C4d after ex-vivo perfusion was attenuated and their post-perfusion levels were significantly lower than those of the control group.

The DDAVP is known to induce $v W F$ secretion from endothelial cells [13]. Porcine vWF is considered a culprit for intravascular thrombosis and 
systemic coagulation in pulmonary xenotransplantation $[9,11]$. Following exposure to human blood, porcine endothelial cells are activated possibly by multiple stimuli, such as ischemic or mechanical injury, and binding of xenoreactive antibodies with or without subsequent complement activation, leading to exposure of pro-coagulant and proinflammatory surfaces and expression or secretion of P-selectin, vWF, and platelet-activating factor [14-16]. Porcine vWF binds to human platelets and induces their activation and aggregation [17]. A study of swine-to-baboon pulmonary xenotransplantation using vWF-deficient donors has shown that vWF-deficient xenografts exhibit interstitial hemorrhage and edema instead of intravascular thrombosis, one of the typical features of pulmonary xenotransplantation rejection [9]. This suggests that porcine $\mathrm{vWF}$ is the key molecule for the development of intravascular thrombosis in pulmonary xenografts. In previous study, we demonstrated that pre-treatment of donor swine with DDAVP reduces the content of $\mathrm{VWF}$ in swine lung without up-regulation of $\mathrm{vWF}$ synthesis [12]. The DDAVP treatment of donor swine reduced the content of $\mathrm{vWF} \mathrm{Ag}$ in porcine lung tissue by $52 \%$ (DDAVP-treated group vs. control group, $7.7 \pm 2.4 \mathrm{AU} / \mathrm{mg}$ vs. $16.0 \pm 5.6 \mathrm{AU} / \mathrm{mg}$ ). We speculate that about $50 \%$ of vWF would be left in porcine lung tissue after treatment even though the exact distribution and functional impact is unknown. We have previously shown that DDAVP pre-treatment of donor swine attenuates the decrease of blood platelet counts in swine-tocanine pulmonary xenotransplantation [12]. In this study, DDAVP pre-treatment could not prevent the decrease of platelet counts in human blood after ex-vivo perfusion. However, it certainly reduced the increase of PF4 which is a platelet activation marker. D-dimer, a marker of systemic intravascular coagulation, remained in the normal range in the perfusion of DDAVP pre-treated porcine lungs, while it frequently increased in that of control lungs. These beneficial effects of DDAVP which were shown not only in the contact with canine blood but also in that with human blood can be attributable to the possible reduction of $\mathrm{vWF}$ content in xenografts by DDAVP treatment.

Porcine vWF is also known to contain $\alpha \mathrm{Gal}$, a major antigen for xenoreactive antibodies [18]. When activated, porcine pulmonary endothelial cells shed vWF along with other membrane proteins [11], which forms circulating immune complexes with xenoreactive antibodies, leading to type III immune complex disease and disseminated intravascular coagulation [11]. To further explore the DDAVP effect on the formation of immune complexes, we first tried to demonstrate the presence of circulating porcine- $\mathrm{vWF} / \mathrm{IgM}$ immune complex in blood by ELISA but failed to get a positive signal. Next, we tried to measure the amount of $\alpha \mathrm{Gal}$ released into circulating blood by ELISA using GSL I-isolectin $\mathrm{B}_{4}$. Disappointingly, $\alpha \mathrm{Gal}$ was not detected in blood samples from the ex-vivo perfusion model. However, the signal in the positive control well tested in parallel was clearly positive. We assumed that the concentration of released $\alpha \mathrm{Gal}$ was too low to be detected by our ELISA system. Consequently, we designed a perfusate retaining model to concentrate $\alpha \mathrm{Gal}$ in the blood. Soluble $\alpha$ Gal was not detected in blood samples obtained before retention but it was obviously detectable by ELISA in samples obtained after retention. Its concentration was significantly higher in the control group than in the DDAVP group. This finding demonstrates that DDAVP pre-treatment reduces the release of $\alpha \mathrm{Gal}$ from xenografts into the circulation. We speculate that shed porcine vWF would be an important source of circulating $\alpha \mathrm{Gal}$ in xenotransplantation and partial depletion of $v W F$ by DDAVP provides a benefit in the reduction of $\alpha \mathrm{Gal}$ release and its immune complex formation, and in the prevention of subsequent complement and coagulation activation. Lower level of $\mathrm{C} 3 \mathrm{a}$ and $\mathrm{C} 4 \mathrm{~d}$ in the perfusate of DDAVP group is consistent with our speculation. These findings support the implication of porcine $\mathrm{vWF}$ for intravascular thrombosis and systemic complement/coagulation abnormalities in pulmonary xenotransplantation.

Porcine $\alpha \mathrm{Gal}$ epitope has the carbohydrate structure similar to blood type B, and anti-B antibodies in $\mathrm{A}$ and $\mathrm{O}$ individuals can recognize both epitopes of $\alpha \mathrm{Gal}$ and blood type B [19]. Actually, the antibody to recognize both $\alpha \mathrm{Gal}$ and blood type B comprises about $85 \%$ of natural anti$\mathrm{B}$ antibodies in $\mathrm{A}$ and $\mathrm{O}$ individuals. Because we didn't have any attempt to inhibit xenoreactive antibodies and complement in this study, we were afraid of possible massive hyperacute rejection initiated by anti-B antibodies. Blood type AB human blood would be the best to avoid any effect of $\mathrm{ABO}$ mismatch but the low frequency of $\mathrm{AB}$ type in our population forced us to recruit donors with blood type B as a practical alternate. As for donor animal, we should have used blood type $\mathrm{O}$ swine, but in our situation, the pigs bred for experimental purpose were not available and we had to use farm pigs. In this process, the selection of certain blood type of swine was impossible for us. Accordingly, we cannot exclude the possibility that anti-A antibodies along with anti- $\alpha \mathrm{Gal}$ 
antibodies in perfusion blood could have played a role in injury of the lung in the case of blood type A swine.

For comparisons between groups, we used mixed model, a type of repeated measures analysis. Its advantage is applicability to the analysis of unbalanced data. The data of repeated measurements from a subject have autocorrelation. Analysis of longitudinal or repeated measures data for balanced study design can be done using repeated measures analysis of variance. However, balanced data sets are rarely obtained in studies and have caused serious statistical analysis problem. The basic theory on which mixed model are based holds with unbalanced data. In this study, we compared the trend of the data according to the elapsing time, not the data at a given time point. Accordingly, some data set at a given time looked inconsistent with the P-value which reflected significance of difference between groups for whole experimental duration.

Pulmanary vascular resistance (PVR) is an important variable of lung function but there was no difference in the PVR between groups in this study. This is not surprising given the fact that there was no attempt to inhibit antibodies or complement. However, in our perfusion setting, the graft should be perfused gently by increasing perfusion flow gradually at the beginning. As a consequence, PVR and other hemodynamic changes earlier than 5 to $10 \mathrm{~min}$ of perfusion were not completely evaluated. Therefore, there might be a more subtle effect on PVR early in the first minutes of perfusion, which we might have missed. Further improvement of ex-vivo perfusion setting is necessary to evaluate earlier events of perfusion.

In this study, we clearly demonstrated the beneficial effect of DDAVP pre-treatment in pulmonary xenotransplantation using an ex-vivo perfusion model despite no additional strategies against either xenoreactive antibodies or complement activation. Additionally, pre-treatment of donor swine would not impose any harm on the recipient. Although vWF depletion by DDAVP would have a temporary and limited effect in preventing pulmonary xenograft dysfunction, theoretically, the reduction of initial inflammation in the graft would be desirable to minimize acute or chronic rejection. So far, no single strategy has been successful in prolonging the survival of pulmonary xenotransplantation and multi-strategic approaches are needed. Therefore, modulation of vWF is expected to provide an additional benefit to pulmonary xenotransplantation using genetically modified swine lacking $\alpha \mathrm{Gal}$ expression and/ or expressing human complement regulatory proteins.

\section{Acknowledgments}

This study was supported by a grant of the Korea Health 21 R\&D Project, Ministry of Health \& Welfare, Republic of Korea (Project No.: A040004) and by National R\&D Program Grant of the Ministry of Science and Technology (Project No.: F104AD010011-06A0401-01110).

\section{References}

1. Lam TT, Hausen B, Boeke-Purkis K et al. Hyperacute rejection of hDAF-transgenic pig organ xenografts in cynomolgus monkeys: influence of pre-existing anti-pig antibodies and prevention by the alpha GAL glycoconjugate GAS914. Xenotransplantation 2004; 11: 517.

2. McGregor CG, Davies WR, Oi $\mathrm{K}$ et al. Cardiac xenotransplantation: recent preclinical progress with 3-month median survival. J Thorac Cardiovasc Surg 2005; 130: 844 .

3. Kuwaki K, Tseng YL, Dor FJ et al. Heart transplantation in baboons using alpha1,3-galactosyltransferase geneknockout pigs as donors: initial experience. Nat Med 2005; 11: 29.

4. Tseng YL, Kuwaki K, Dor FJ et al. Alpha1,3-Galactosyltransferase gene-knockout pig heart transplantation in baboons with survival approaching 6 months. Transplantation 2005; 80: 1493.

5. Chen G, Qian H, Starzl $\mathrm{T}$ et al. Acute rejection is associated with antibodies to non-Gal antigens in baboons using Gal-knockout pig kidneys. Nat Med 2005; 11: 1295.

6. Pfeiffer S, Zorn GL III, Blair KS et al. Hyperacute lung rejection in the pig-to-human model 4: evidence for complement and antibody independent mechanisms. Transplantation 2005; 79: 662.

7. Schroeder C, Allan JS, Nguyen BN et al. Hyperacute rejection is attenuated in GalT knockout swine lungs perfused ex vivo with human blood. Transplant Proc 2005; 37: 512 .

8. Lau CL, Daggett WC, Yeatman MF et al. The role of antibodies in dysfunction of pig-to-baboon pulmonary transplants. J Thorac Cardiovasc Surg 2000; 120: 29.

9. Lau CL, Cantu E III, Gonzalez-Stawinski GV et al. The role of antibodies and von Willebrand factor in discordant pulmonary xenotransplantation. Am J Transplant 2003; 3: 1065.

10. Cowan PJ, Shinkel TA, Witort EJ, Barlow H, Pearse MJ, D'APICE AJ. Targeting gene expression to endothelial cells in transgenic mice using the human intercellular adhesion molecule 2 promoter. Transplantation 1996; 62: 155.

11. Holzknecht ZE, Coombes S, Blocher BA et al. Immune complex formation after xenotransplantation: evidence of type III as well as type II immune reactions provide clues to pathophysiology. Am J Pathol 2001; 158: 627.

12. Kang HJ, Lee G, Kim JY et al. Pre-treatment of donor with 1-deamino-8-d-arginine vasopressin could alleviate early failure of porcine xenograft in a cobra venom factor treated canine recipient. Eur J Cardiothorac Surg 2005; 28: 149. 
13. Kaufmann Je, Oksche A, Wollheim CB, Gunther G, ROSENTHAL W, VISCHER UM. Vasopressin-induced von Willebrand factor secretion from endothelial cells involves V2 receptors and cAMP. J Clin Invest 2000; 106: 107.

14. Pober JS, Cotran RS. The role of endothelial cells in inflammation. Transplantation 1990; 50: 537.

15. BaCh FH, Robson SC, Ferran C et al. Endothelial cell activation and thromboregulation during xenograft rejection. Immunol Rev 1994; 141: 5.

16. BANZ Y, RIEBEN R. Endothelial cell protection in xenotransplantation: looking after a key player in rejection. Xenotransplantation 2006; 13: 19.
17. Mazzucato M, De Marco L, Pradella P, Masotti A, PARETI FI. Porcine von Willebrand factor binding to human platelet GPIb induces transmembrane calcium influx. Thromb Haemost 1996; 75: 655.

18. Holzknecht ZE, Platt JL. Identification of porcine endothelial cell membrane antigens recognized by human xenoreactive natural antibodies. J Immunol 1995; 154: 4565 .

19. Galili U, Buehler J, Shohet SB, Macher BA. The human natural anti-Gal IgG. III. The subtlety of immune tolerance in man as demonstrated by crossreactivity between natural anti-Gal and anti-B antibodies. J Exp Med 1987; 165: 693. 